Original Article

\title{
COMPARISION OF MYO-INOSITOL VERSUS METFORMIN ON ANTHROPOMETRIC PARAMETERS IN POLYCYSTIC OVARIAN SYNDROME IN WOMEN
}

\author{
JYOTI NEHRA*, JYOTI KAUSHAL*, SAVITA RANI SINGHAL ${ }^{* *}$, VEENA SINGH GHALAUT ${ }^{* * *}$ \\ *Department of Pharmacology, Pt. B. D. Sharma PGIMS, Rohtak, **Department of Obstetrics and Gynaecology, Pt. B. D. Sharma PGIMS, \\ Rohtak, ***Department of Biochemistry, Pt. B. D. Sharma PGIMS, Rohtak \\ Email: jyotinhr7@gmail.com
}

Received: 27 Nov 2016 Revised and Accepted: 27 Feb 2017

\section{ABSTRACT}

Objective: The objective of the study was to evaluate and compare the effect of insulin sensitizers i.e. metformin and myoinositol on anthropometric parameters in patients of the Polycystic ovarian syndrome (PCOS).

Methods: A prospective, open-labeled, randomized, comparative, clinical study was conducted on 60 patients. The patients were randomly divided into two groups of 30 each to receive either of the following two treatments: group A: Tablet myoinositol $1 \mathrm{~g}$ twice daily. group B: Tablet metformin $500 \mathrm{mg}$ thrice daily for $24 \mathrm{w}$. Anthropometric parameters were assessed by measuring body weight, Body mass index (BMI), waist circumference, hip circumference, waist-hip ratio (WHR) at baseline and subsequently at the end of $12 \mathrm{w}$ and $24 \mathrm{w}$.

Results: In both the groups, there was a statistically significant improvement in over a period of $24 \mathrm{w}$. In group A, the values for weight at baseline, $12 \mathrm{w}$ and $24 \mathrm{w}$ expressed in mean \pm SEM are $63.96 \pm .90,62.33 \pm .88$ and $61.20 \pm .85$ while in group $\mathrm{B}$ the values were $63.58 \pm 1.88,62.26 \pm 1.74$ and $60.86 \pm 1.65$. In group $\mathrm{A}$, the values for BMI at baseline, $12 \mathrm{w}$ and $24 \mathrm{w}$ were $26.45 \pm .41,25.78 \pm .42$ and $25.31 \pm .40$ while in group $B$ the values were $26.09 \pm .76,25.53 \pm .71$ and $24.96 \pm .68$ respectively. In group A, WHR values were $0.79 \pm .007,0.78 \pm .007$ and $0.78 \pm .007$ while in group B $0.79 \pm .010$, $0.79 \pm 0.108,0.79 \pm .011$ at baseline, $12 \mathrm{w}$ and $24 \mathrm{w}$ respectively. However, on comparing both the groups at 12 and $24 \mathrm{w}$, no statistically significant difference was observed in all the parameters.

Conclusion: There was a definite improvement in anthropometric parameters with both metformin and myoinositol but on comparing these drugs, no significant difference was observed. Thus, myoinositol can also be used as an alternative to metformin for the treatment of PCOS.

Keywords: PCOS, BMI, WHR, Myo-inositol, Metformin, Anthropometric

(C) 2017 The Authors. Published by Innovare Academic Sciences Pvt Ltd. This is an open access article under the CC BY license (http://creativecommons.org/licenses/by/4. 0/] DOI: http://dx.doi.org/10.22159/ijpps.2017v9i4.16359

\section{INTRODUCTION}

Polycystic ovary syndrome (PCOS) is the most common endocrine disorder among women of reproductive age. More than $30 \%$ of women with PCOS are obese (body mass index-BMI $>30 \mathrm{~kg} / \mathrm{m}^{2}$ ), reflecting primarily visceral adiposity [1]. Obesity is a prominent feature of PCOS, occurring in $40-50 \%$ of PCOS patients $[2,3]$. Prevalence of PCOS is increased in overweight and obese women when compared to their lean counterparts. The prevalence rates of PCOS in underweight, normal-weight, overweight, and obese women are $8.2 \%, 9.8 \%, 9.9 \%$ and $9.0 \%$ respectively. Prevalence rates are $12.4 \%$ and $11.5 \%$ in women with BMI $35-40 \mathrm{~kg} / \mathrm{m}^{2}$ and greater than $40 \mathrm{~kg} / \mathrm{m}^{2}[4]$.

Increased adiposity, particularly visceral adiposity that is reflected by an elevated waist circumference $(>88 \mathrm{~cm})$ or waist-to-hip ratio (WHR), has been associated with hyperandrogenemia, insulin resistance, glucose intolerance, and dyslipidemia [5]. Genes that are involved in the pathogenesis of PCOS include genes associated with steroidogenesis, regulation of gonadotropin secretion, effects of insulin, obesity, factors regulating the body's energy expenditure and the genes associated with chronic inflammation [6]. PCOS women tend to have an increased BMI and WHR i.e. abdominal (visceral) obesity $[7,8]$. Anthropometric parameters suggesting insulin resistance are obesity (increased BMI) and WHR $>0.85$. Numerous studies have demonstrated a pathogenetic association of PCOS with insulin resistance and hyperinsulinaemia [9-11].

Metformin and myoinositol being insulin sensitizers improve the metabolic, reproductive and anthropometric parameters i.e. weight, BMI and WHR in women suffering from PCOS $[12,13]$. Efficacy and safety of myoinositol and metformin is already established in various studies. Some studies have shown the comparable efficacy of these drugs regarding the improvement of clinical features, hormonal parameters and biochemical parameters. The safety profile is shown to be better with myoinositol than metformin [14]. It is well known that metformin an insulin sensitizer causes weight loss. This study was planned to determine whether myoinositol has also got the beneficial effect on anthropometric parameters and to compare the effect of metformin and myoinositol on anthropometric parameters in PCOS women.

\section{MATERIALS AND METHODS}

This was a prospective, open-label, randomized, a comparative clinical study conducted by the department of Pharmacology and Obstetrics and Gynaecology, Pt. B. D. Sharma PGIMS, Rohtak on 60 patients. The study was in accordance with the principles of good clinical practice (ICH-GCP) and declaration of Helsinki. An informed consent was obtained from all patients enrolled for the study. The study was approved by the PG Board of Studies, Pharmacology and Dean Faculty in Paraclinical Sciences, University of Health Sciences, Rohtak vide letter No. Micro/2014/738-42 dated 07.05.2014.

The inclusion criteria included females of reproductive age group (15-45 y), diagnosed with PCOS according to Androgen Excess Society (AES)/2006 criteria: presence of hyperandrogenism (clinical and/or biochemical), oligo or anovulation, polycystic ovarian morphology (PCOM)-at least one ovary with 12 or more follicles (2-9 $\mathrm{mm}$ in diameter) or ovarian volume $>10 \mathrm{ml}$ and those willing to give a written informed consent. The exclusion criteria were: women suffering from any neoplastic disease, hyperprolactinemia, Cushing's disease, hypothyroidism/hyperthyroidism, pregnant and nursing mothers, active liver disease, renal impairment, established type 1 or type 2 diabetes mellitus, any history of drug intake of antidiabetic or estrogen and progesterone, history of any treatment taken in last $3 \mathrm{mo}$, smokers and alcoholic subjects and patients who were unable to come for regular follow-ups. 
An adequate number of patients were screened and selected as per the inclusion and exclusion criteria for the study. The eligible patients were randomly divided into two study groups each to receive either of the following two treatments: group A: Tablet myoinositol $1 \mathrm{~g}$ twice daily and group B: Tablet metformin $500 \mathrm{mg}$ thrice daily for 6 mo with the help of computer-generated random numbers. Each study group had minimally 30 patients who completed the study as per the protocol. During the study, patients were not permitted to take any non-study drugs. Anthropometric parameters were assessed by measuring body weight, BMI, waist circumference, hip circumference, WHR at baseline and subsequently at the end of $12 \mathrm{w}$ and $24 \mathrm{w}$. BMI is calculated as body weight in kilogrammes divided by square of height in meters. Waist circumference is measured with a tape midway between the lowest rib margin and the iliac crest in standing position. The hip circumference is measured over the widest part of gluteal region.

Data was expressed as mean \pm SEM. Both intragroup and intergroup statistical analysis was done. Intragroup analysis for repeated measures was done using ANOVA for parametric data and pairwise comparison was done. Intergroup analysis was done using unpaired ' $\mathrm{t}$ ' test for parametric data. A p-value $<0.05$ was considered as statistically significant.

\section{RESULTS}

A total of 79 patients with symptoms of PCOS were screened for this study. Out of this, 8 patients were excluded, as 6 patients did not fulfil the predefined inclusion criteria of the study and 2 were not willing to give informed consent. Rest of the 71 patients, enrolled in the study were randomized with the help of computer-generated random numbers and were allocated to either of the two treatment groups. Patients in group A received myoinositol $1 \mathrm{gm}$ twice a day while group B received metformin $500 \mathrm{mg}$ thrice a day for $24 \mathrm{w}$. Of the 71 patients enrolled in the study, 35 were allocated to group A and 36 allocated to group B. 5 patients in group A and 6 patients in group B were lost to follow-up and were dropped from the study and the remaining 30 patients in either group completed the treatment successfully. The baseline characteristics of the patients are tabulated in table I.

Table 1: Comparison of study population characteristics in both the groups

\begin{tabular}{lll}
\hline Variables & Group A Myo-inositol (n=30) & Group B Metformin (n=30) \\
\hline Age in years & $23.8 \pm 0.69$ & $23.26 \pm 1.03$ \\
Weight $(\mathrm{kg})$ & $63.96 \pm 0.90$ & $63.58 \pm 1.88$ \\
BMI $\left(\mathrm{kg} / \mathrm{m}^{2}\right)$ & $26.45 \pm 0.41$ & $26.09 \pm 0.76$ \\
Marital Status & & \\
Married & 19 & 22 \\
Unmarried & 11 & 8 \\
Education & & \\
Literate & 26 & 28 \\
Illiterate & 4 & 2 \\
Age at menarche & $11.8 \pm 0.29$ & $11.1 \pm 0.21$ \\
Number of patients with Irregular cycle & 25 & 24 \\
mFG score of Hirsutism & $9.03 \pm 0.32$ & $9.06 \pm 0.46$ \\
\hline
\end{tabular}

Age, weight, BMI, mFG score are expressed as mean \pm SEM, Group A: Myo-inositol 1000 mg bd, Group B: Metformin 500 mg tds

There was a statistically significant improvement in anthropometric parameters as assessed by changes in body weight, BMI and WHR with both the drugs over a period of $24 \mathrm{w}$. Anthropometric parameters were slightly better improved with myoinositol than metformin.

Fig. 1 shows changes in body weight (kg) with both the drugs over a period of $24 \mathrm{w}$. There was a statistically significant reduction in weight at the end of 12 and $24 \mathrm{w}$ compared to baseline values in both the groups, however, difference is not statistically significant. In group A and $B$ mean decrease in weight was 1.63 and 1.32 respectively at the end of $12 \mathrm{w}$. With myoinositol mean reduction in weight was from 63.96 (baseline) to 61.20 (24weeks), showed a decrease of 2.76. Mean reduction in weight was from 63.58 (baseline) to 60.86 (24 w), showed a decrease of 2.72 in the metformin group.

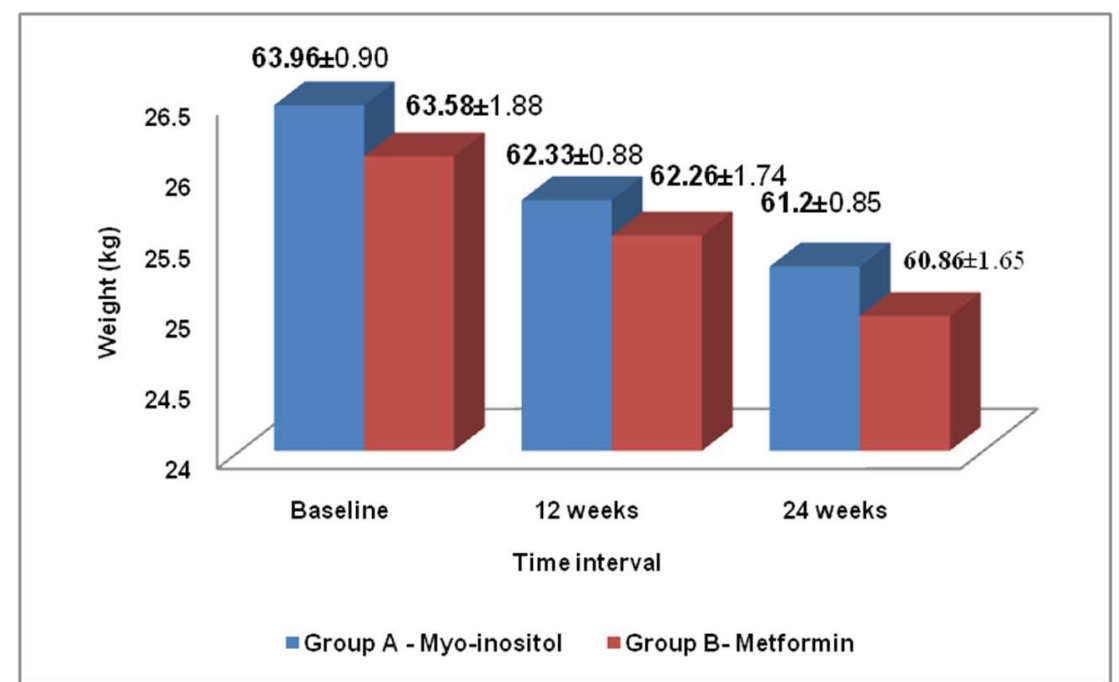

Fig. 1: Comparison of changes in weight in both the groups, Values are expressed as mean \pm SEM, Group A (n=30): Myo-inositol 1000 mg bd, Group B ( $(n=30)$ : Metformin 500 mg tds 


\section{Intragroup analysis}

*Comparison of values at the end of week 12 and 24 with baseline values is statistically significant $(\mathrm{P}<0.05)$.

\section{Intergroup analysis}

Comparison of values between Group A and B is not statistically significant $(\mathrm{P}>0.05)$.
Fig. 2 shows changes in BMI $\left(\mathrm{kg} / \mathrm{m}^{2}\right)$ with both the drugs over a period of $24 \mathrm{w}$. In myoinositol group, the BMI decreased by 1.14 , while in metformin group the BMI decreased by 1.13 at the end of $24 \mathrm{w}$ as compared to baseline values. There was slightly more improvement in BMI with myoinositol than metformin (1.14 vs 1.13) at the end of $24 \mathrm{w}$, but the the difference was not statistically significant.

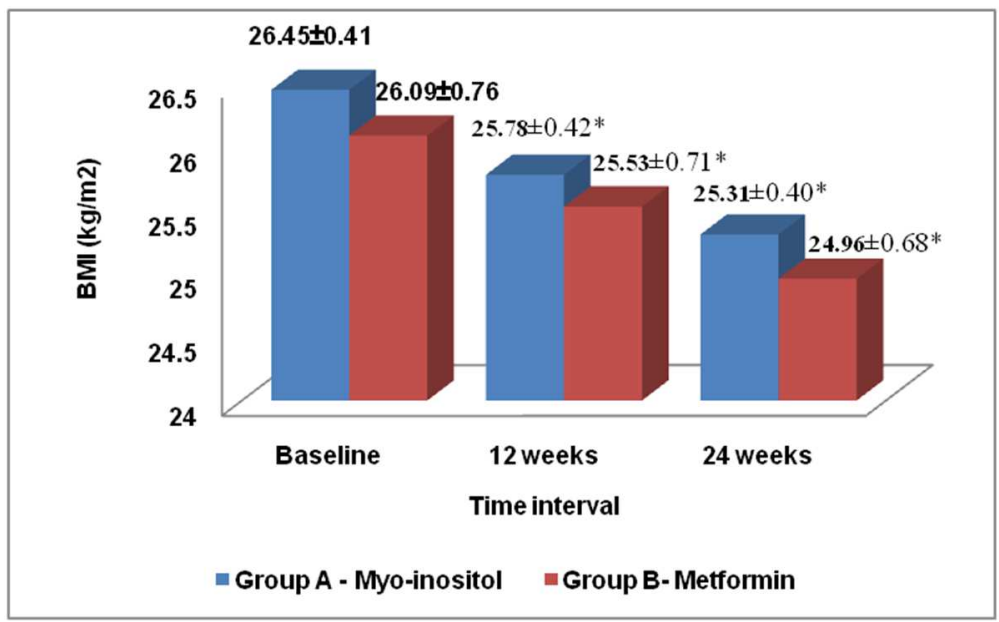

Fig. 2: Comparison of changes in BMI in both the groups, Values are expressed as mean \pm SEM, Group A (n=30): Myo-inositol 1000 mg bd, Group B (n=30): Metformin $500 \mathrm{mg}$ tds

\section{Intragroup analysis}

*Comparison of values at the end of week 12 and 24 with baseline values is statistically significant $(\mathrm{P}<0.05)$.

\section{Intergroup analysis}

Comparison of values between Group A and B is not statistically significant $(\mathrm{P}>0.05)$.

Table 2 shows changes in waist circumference and hip circumference followed by WHR over a period of $24 \mathrm{w}$. WHR decreased by 0.01 with myoinositol at the end of $12 \mathrm{w}$ which was maintained over a period of $24 \mathrm{w}$ whereas in metformin group no reduction in WHR was observed at the end of $24 \mathrm{w}$ as compared to baseline values.

\section{Intragroup analysis}

Comparison of values at the end of week 12 and 24 with baseline values is not statistically significant $(\mathrm{P}>0.05)$.

\section{Intergroup analysis}

Comparison of values between Group A and B is not statistically significant $(\mathrm{P}>0.05)$.

Table 2: Comparison of changes in waist-hip ratio (WHR) in both the groups

\begin{tabular}{|c|c|c|c|c|c|c|}
\hline \multirow[t]{2}{*}{ Parameters } & & \multirow{2}{*}{$\begin{array}{l}\text { Myo-inositol } \\
\text { Group A }(n=30) \\
\text { mean } \pm \text { SEM } \\
\end{array}$} & \multirow{2}{*}{$\begin{array}{l}\text { Metformin } \\
\text { Group B }(n=30) \\
\text { mean } \pm \text { SEM } \\
\end{array}$} & \multirow{2}{*}{$\begin{array}{l}\text { P value } \\
\text { (inter-group) } \\
\end{array}$} & \multicolumn{2}{|c|}{$\begin{array}{l}95 \% \text { confidence interval of } \\
\text { difference }\end{array}$} \\
\hline & & & & & lower & upper \\
\hline \multirow[t]{3}{*}{ Waist circumference $(\mathrm{cm})$} & Baseline & $77.56 \pm 1.58$ & $78.08 \pm 1.80$ & 0.830 & -5.32 & 4.29 \\
\hline & $12 \mathrm{w}$ & $76.13 \pm 1.54$ & $76.46 \pm 1.77$ & 0.888 & -5.04 & 4.37 \\
\hline & $24 \mathrm{w}$ & $74.86 \pm 1.44$ & $74.90 \pm 1.72$ & 0.988 & -4.53 & 4.46 \\
\hline \multirow[t]{3}{*}{ Hip circumference $(\mathrm{cm})$} & Baseline & $97.13 \pm 1.41$ & $97.41 \pm 1.72$ & 0.899 & -4.74 & 4.17 \\
\hline & $12 \mathrm{w}$ & $96.23 \pm 1.37$ & $95.93 \pm 1.69$ & 0.891 & -4.06 & 4.66 \\
\hline & $24 \mathrm{w}$ & $94.93 \pm 1.32$ & $94.73 \pm 1.66$ & 0.926 & -4.06 & 4.66 \\
\hline Waist hip ratio & Baseline & $0.79 \pm 0.007$ & $0.79 \pm .010$ & 0.847 & -0.028 & 0.023 \\
\hline \multirow[t]{2}{*}{$(\mathrm{WHR})$} & $12 \mathrm{w}$ & $0.78 \pm 0.007$ & $0.79 \pm .0108$ & 0.610 & -0.033 & 0.019 \\
\hline & $24 \mathrm{w}$ & $0.78 \pm 0.007$ & $0.79 \pm 0.011$ & 0.836 & -0.029 & 0.023 \\
\hline
\end{tabular}

All values are expressed as mean \pm SEM, Group A: Myo-inositol $1000 \mathrm{mg}$ bd, Group B: Metformin $500 \mathrm{mg}$ tds

\section{DISCUSSION}

PCOS is the most common endocrine disorder among women of reproductive age, is considered to be not only a reproductive endocrinopathy but also a metabolic disorder. Insulin resistance occurs in around $50 \%$ to $80 \%$ of women with PCOS, [15] primarily in the more severe National Institute of Health (NIH) diagnosed PCOS and in those who are overweight. The risk of gestational diabetes mellitus (GDM) is increased and is further exacerbated by obesity $[9,16]$. There is a close association between insulin resistance (IR) and obesity. In PCOS, obesity worsens insulin resistance and exacerbates reproductive and metabolic features. The gyneoid type of fat distribution develops during female puberty and persists during the fertile phase of adult life [17]. Peripheral fat tissue, especially in the lower body region is an important source of extra ovarian estrogen synthesis because aromatization from androgens to estrogens takes place there [17]. The major endocrine symptom of PCOS, hyperandrogenicity is clearly associated with a preponderance of fat localized in the upper body sites. This sexspecific fat distribution, commonly called android fat distribution, is 
associated with obesity and a variety of metabolic characteristics as well as an indicator of reduced reproductive capability of the woman [17]. Upper-body obesity is a key component of the IR syndrome. Abdominal fat distribution is measured by Waist-hip ratio (WHR) which gets altered in insulin resistance.

$5 \%$ to $10 \%$ weight loss has significant clinical benefits improving psychological outcomes, reproductive features (menstrual cyclicity, ovulation and fertility) and metabolic features (insulin resistance and risk factors for cardiovascular disease and type II DM).) [18]

More than $50 \%$ of PCOS patients are obese. These women are at the risk of diabetes, atherosclerosis, and cardiovascular diseases. Since obesity is the most common cause of insulin resistance and hyperandrogenism, weight reduction might be the first recommendation for PCOS women. Weight loss up to 5-7\% during 6 mo can restore ovulation and fertility in more than $75 \%$ women.

In our study, there was a statistically significant reduction in BMI at 12 and $24 \mathrm{w}$ compared to baseline values in both the groups. Mean decrease in BMI was 0.67 and 0.56 respectively at the end of $12 \mathrm{w}$ with myoinositol and metformin respectively. In myoinositol group mean reduction in BMI was from 26.45 (baseline) to 25.31 ( $24 \mathrm{w}$ ), showed a decrease of 1.14. In metformin group mean reduction in BMI was from 26.09 (baseline) to 24.96 ( $24 \mathrm{w}$ ), showed a decrease of 1.13 .

In a study done by Awalekar et al., in which 102 patients were randomized into three groups i.e. metformin (500 mg tds), myoinositol (2 $\mathrm{g}$ bd) plus folic acid (5 $\mathrm{mg}$ od) and lifestyle modification group for a period of $12 \mathrm{w}$. BMI decreased by 2.51 and 1.00 with metformin and myoinositol respectively [19]. The findings of our study are similar to above-quoted study as BMI was reduced with both the drugs at the end of $12 \mathrm{w}$ in both the studies. But the decrease was more with metformin in a study done by Awalekar et al. as compared to the present study (2.51 vs 0.56 ). The decrease in BMI was also more with myoinositol in above-quoted study as compared to our study (1 vs 0.67 ).

In a study done by Genazzani et al., in 20 PCOS patients, who were randomly assigned to receive either myoinositol $2000 \mathrm{mg}$ plus folic acid $200 \mu \mathrm{g}$ daily or folic acid $200 \mu \mathrm{g}$ daily for a period of $12 \mathrm{w}$ changes in BMI were observed. BMI decreased by 0.70 with myoinositol, whereas increased by 0.10 with folic acid [20].

The findings of our study are similar to above-quoted study as BMI was reduced with myoinositol at the end of $12 \mathrm{w}$ in both the studies. The decrease in BMI in a study done by Genazzani et al. is in concordance with the present study ( 0.70 vs 0.67 ).

In another study done by Genazzani et al., 34 patients were given a combination of alpha-lipoic acid $(400 \mathrm{mg})$ and myoinositol $1 \mathrm{~g}$ every day for $12 \mathrm{w}$. BMI decreased by 0.50 at the end of $12 \mathrm{w}$ [21]. The findings of our study are similar to above-quoted study as BMI reduced with myoinositol at the end of $12 \mathrm{w}$ in both the studies. However the decrease in BMI in a study done by Genazzani et al. is less as compared to the present study ( 0.50 vs 0.67$)$. This could be due to the fact that dose of myoinositol given in above study (1g) was less than our study ( $2 \mathrm{~g})$.

There was a slight reduction in WHR at the end of $12 \mathrm{w}$ (0.01), which was maintained over a period of $24 \mathrm{w}$ compared to baseline values in myoinositol group. In metformin group, there was no reduction in WHR at the end of 12 and $24 \mathrm{w}$.

In a study done by Angik et al., in which metformin and myoinositol were compared to observe their effects on WHR, 100 patients were randomly allocated to treatment with either myoinositol or metformin. Myo-inositol group received $1 \mathrm{~g}$ twice daily while metformin group received $500 \mathrm{mg}$ twice daily for $6 \mathrm{mo}$, in which metformin and myoinositol were compared to observe their effects on WHR. The WHR increased by 0.10 in myoinositol group whereas decreased by 0.03 with metformin at the end of $24 \mathrm{w}$, however changes in WHR were not significant in both the groups [22] The findings of our study differ from above-quoted study in the context that slight better response was observed with myoinositol in our study whereas that was with metformin in above-mentioned study. However, the similarity is that no statistically significant change was observed in WHR over a period of $24 \mathrm{w}$ with both the drugs.
In a study done by Gerli et al., 45 PCOS patients were given myoinositol combined with folic acid $2 \mathrm{~g}$ bd and 47 were given folic acid as placebo and observed after $14 \mathrm{w}$. There was no change seen in both the groups at the end of $14 \mathrm{w}$ [13]. The findings of our study are in concordance with the above-mentioned study as no significant change was observed in WHR with myoinositol.

The results of present study indicate that both metformin and myoinositol led to improvement in anthropometric parameters over the period of $24 \mathrm{w}$. As the difference in all these parameters found to be statistically non-significant when compared, hence myoinositol can be considered comparable to metformin in the treatment of PCOS. Though the sample size and study duration were small in this study, further research with larger groups and longer study period is required to support these findings.

\section{CONCLUSION}

Polycystic ovarian syndrome (PCOS) is a common endocrine disorder in women of reproductive age associated with insulin resistance leading to hyperandrogenism, anovulation, infertility and weight gain. As an improvement in insulin resistance helps in weight reduction and vice versa. Metformin and myoinositol being insulin sensitizers improved anthropometric parameters in PCOS. Both the drugs were found to be equally efficacious.

Hence, myoinositol can be a new addition in the armamentarium for the treatment of PCOS. As insulin resistance is the underlying pathology in PCOS, insulin sensitizers along with lifestyle modification should be considered as a new integrative strategy which can lead to weight reduction and improvement in symptoms of PCOS.

\section{CONFLICT OF INTERESTS}

All the authors declare that there is no conflict of interest.

\section{REFERENCES}

1. Gambineri A, Pelusi C, Vicennati V, Pagotto U, Pasquali R. Obesity and the polycystic ovary syndrome. Int J Obes Relat Metab Disord 2002;26:883-96.

2. Hsu MI, Liou TH, Liang SJ, Su HW. Inappropriate gonadotropin secretion in polycystic ovary syndrome. Fertil Steril 2009;91:1168-74.

3. Yildiz BO, Knochenhauer ES, Azziz R. Impact of obesity on the risk for polycystic ovary syndrome. J Clin Endocrinol Metab 2008;93:162-8.

4. National Cholesterol Education Program Expert Panel on Detection, Evaluation, and Treatment of High Blood Cholesterol in Adults. Circulation 2002;106:3143-6.

5. Rebuffe-Scrive M, Cullberg G, Lundberg PA. Anthropometric variables and metabolism in polycystic ovarian disease. Horm Metab Res 1989;21:391-7.

6. Escobar-Morreale HF, Luque-Ramirez M, San Millan JL. The molecular genetic basis of functional hyperandrogenism and the polycystic ovary syndrome. Endocr Rev 2005;26:251-82.

7. Bringer J, Lefebvre P, Boulet F, Grigorescu F. Body composition and regional fat distribution in polycystic ovarian syndrome. Relationship to hormonal and metabolic profiles. Ann N Y Acad Sci 1993;687:115-23.

8. Bouchard C, Despres JP, Mauriege P. Genetic and non genetic determinants of regional fat distribution. Endoc Rev 1993;14:72-93.

9. Legro RS, Kunselman AR, Dodson WC, Dunaif A. Prevalence and predictors of risk for type 2 diabetes mellitus and impaired glucose tolerance in polycystic ovary syndrome. J Clin Endocrinol Metab 1999;84:165-9.

10. Barbieri RL. Induction of ovulation in infertile women with hyperandrogenism and insulin resistance. Am J Obstet Gynecol 2000;183:1412-8.

11. Gennarelli G, Holte J, Berglund L, Berne C. Prediction models for insulin resistance in the polycystic ovary syndrome. Hum Reprod 2000;15:2098-102.

12. Nazari T, Bayat R, Hamedi M. Metformin therapy in girls with polycystic ovary syndrome: a self-controlled clinical trial. Arch Iranian Med 2007;10:176-81. 
13. Gerli S, Papaleo E, Ferrari A, Di Renzo GC. Randomised double blind placebo controlled trial: effects of myoinositol on ovarian function and metabolic factors in women with PCOS. Eur Rev 2007; 11:347-54.

14. Nehra J, Kaushal J, Singhal SR, Ghalaut VS. A comparative study of efficacy and safety of myoinositol versus metformin in polycystic ovarian syndrome in women. W J Pharm Pharm Sci 2016;5:884-96

15. Legro RS, Castracane VD, Kauffman RP. Detecting insulin resistance in polycystic ovary syndrome: purposes and pitfalls. Obstet Gynecol Surv 2004;59:141-54

16. Boudreaux MY, Talbott EO, Kip KE, Brooks MM, Witchel SF. Risk of T2DM and impaired fasting glucose among PCOS subjects: results of an 8 y follow-up. Curr Diabetes Rep 2006;6:77-83.

17. Liou TH, Yang JH, Hsieh $\mathrm{CH}$, Lee CY. Clinical and biochemical presentations of polycystic ovary syndrome among obese and nonobese women. Fertil Steril 2009;92:1960-5.

18. Huber-Buchholz MM, Carey DG, Norman RJ. Restoration of reproductive potential by lifestyle modification in obese polycystic ovary syndrome: role of insulin sensitivity and luteinizing hormone. J Clin Endocrinol Metab 1999;84:1470-4.

19. Awalekar J, Awalekar C, Jadhav VM, Chivate CG, Patwardhan MH. Effect of metformin and myoinositol and lifestyle modification in patients of polycystic ovarian disease (PCOD). Int J Biomed Reaser 2015;6:698-704.

20. Genazzani AD, Lanzoni C, Ricchieri F, Jasonni VM. Myoinositol administration positively affects hyperinsulinemia and hormonal parameters in overweight patients with polycystic ovary syndrome. Gynecol Endocrinol 2008;24: 139-44.

21. Genazzani AD, Despini G, Santagni S, Prati A, Rattighieri E, Chierchia E, et al. Effects of a combination of alpha lipoic acid and myoinositol on insulin dynamics in overweight/ obese patients with PCOS. Endocrinol Metabol Syndrome 2014;3:3.

22. Angik R, Jajoo SS, Hariharan C, Chimote A. A comparative study of metabolic and hormonal effects of myoinositol versus metformin in women with polycystic ovary syndrome: a randomized controlled trial. Int J Reprod Contracept Obstet Gynecol 2015;4:189-94.

\section{How to cite this article}

- Jyoti Nehra, Jyoti Kaushal, Savita Rani Singhal, Veena Singh Ghalaut. Comparision of myo-inositol versus metformin on anthropometric parameters in polycystic ovarian syndrome in women. Int J Pharm Pharm Sci 2017;9(4):144-148. 